\title{
HIV-TB CO-INFECTION: PATHOGENESIS, DIAGNOSIS AND MANAGEMENT IN ADULTS
}

\author{
Salami. A.K
}

Department Of Medicine, College Of Medicine, University Of llorin, PMB 1515, llorin

Correspondence to: Dr. Salami. AK, E-mail: salkaz2000@yahoo.com

\begin{abstract}
There is a looming epidemic of HIV/TB co-infection in tandem to the prevailing wave of HIV infection in sub-Saharan Africa and South East Asia where TB is endemic. HIV positive patients become susceptible to Mycobacterial infection following depletion of the immune cells that usually resist mycobacterial infection i.e. $\mathrm{CD4}^{+}$, and macrophages. Host's TH1 immune response to TB produces several cytokines some of which further enhance local and systemic HIV replication. DOTS remain the best option for treating TB in HIV patients. This is sometimes co-administered with antiretroviral (ARV) drugs; however, this is fraught with complex bidirectional drug-drug interactions between rifamycin component of anti-TB regimen and the protease inbribitors (PI) and non-nucleoside reverse transcriptase inhibitors (NNRTI) components of ARV. Some patients could also develop paradoxioal reactions. Cytokine inhibitors, could have an adjunct role to Anti-TB therapy when it roles in the pathogenesis of TB in HIV/TB is fully understood.

KEYWORDS: HIVITB co-infection, pathogenesis, DOTS, HAART, Drug interactions
\end{abstract}

\section{INTROUCTION}

By estimate one third of the world population is infected with Mycobacterium tuberculosis (MTB) and every day 23,000 people develop active TB, i.e. about 8.7 million cases per year (1). Averagely, TB kills 2 million people every year (1). Also about 40million people are HIV infected worldwide with 16,000 people being infected every day (1). TB and HIV have formed a synergy and this is facilitaring the spread of a coepidemic of HIV-TB especially in sub-Saharan Africa and South-East Asia (2.3). HIV positive individuals are 50 times more susceprible to MTB infection, and once infected, are 800 times more likely to develop an active TB (4\&5). About 70\% of all TB cases in sub Saharan Africa are co infected with HIV (1), the highest in the world.
This has impacted heavily on the regional TB control programme with a threat of MDR-TB especially in countries with ineffective DOTS implementation (1). The prevalence of HIV infection in Nigeria is about $5 \%$, this is 4times lower than the estimated $20 \%$ mark of HIN prevalence at which the annual percentage increase in TB will be high at over $10 \%(6)$. However, Nigeria still has the highest annual estimate of new TB cases in Africa with about $27 \%$ of, its adults infected with TB/HIV (7) while South Africa has TB as the leading cause of mortality amongst her HIV infected persons (8). According to WHO, TB accounts for $11 \%$ of all deaths in AIDS patients (9); this makes it one of the leading causes of mortality in HIV infected patients. To effectively control this growing epidemic of HIV/TB, both 
HAART and DOTS should have a wider coverage. These medications will provide lifelines to millions of co-infected people. Clinicians have to be educated and updated on the complex interactions between TB and HIV as well as the dual drug-drug interactions that exist between anti-retroviral and anti-TB drugs.

\section{PATHHOGENESIS}

$M T B$ is the infectious agent of TB and it is acquired through inhalation of acrosolized droplets nuclei produced by patients with pulmonary, bronchial or laryngeal TB when they cough, sneeze, speak, or sing (10). These are the main sources of mycobactcrial transmission, but smear negative PTB and extra pulmonary TB (EPTB) could also transmit the bacilli (11), especially during cough induction (12\&13), irrigation of TB abscesses (14) or changing of wound dressings (15). In most infected individuals the tubercle bacilit remain dormant for years after infection before entering a phase of exponential muhiplication to give active disease (16) Developmem of active TB is often prevented by the host's intact immume system (17), specifically the cell-mediated type (18), but this is the target of HIV infection. In TB/HIV co-infected patients therefore, there will be a steady deterioration in this protective capacity of the cell-mediated immunity till a critical point at which tubercle bacilli begin to proliferate and cause clinical disease (17). That is the balance between quiescent TB focus and the host immunity has broken down and resulted in endogenous reactivation. This occurs with the $\mathrm{CD} 4+$ count around $500 \mathrm{cells} / \mathrm{ul}$ or slightly higher. The ensuing reactivation often manifest as a localized pulmonary form, however, in advanced state of immunosuppression poor containment of the resulting infection could occur with resultant widespread of the bacilli causing extra pulmonary, disseminated or miliary TB (18). When the CD4+ count is less than 500cells/ul (19) active TB could progress rapidly from primary mycobacterial infection (20\&21) and some patients could have exogenous re-infection (22). The estimated annual risk of reactivation among HIV/TB patients is about 5 to $8 \%$ with a cumulative lifetime risk of $30 \%$ or more compared to a cumulative lifetime risk of 5 to $10 \%$ in HIV-negative patients (9). Early in the course of HIV infection reactivation is commoner in the upper lobes or the upper part of the lower lobes of the lungs where ventilation is greatest; $\mathrm{PO}_{2}$ of $140 \mathrm{mmHg}$ (23) and lymphatic drainage is relatively impaired (24\&25) but as the disease progresses it could occur at any earlier seeded site in the body.

HIV and MTB influence each other in a synergistic and bidirectional ways (26). Host immune response to tubercle bacilli enhances both systemic and local HIV replication and tends to acceletate the course of progression of HIV infection (26\&27). Mechanisms of these interactions are now being understood. The initial contact between the host immune system and MTB occurs in the alveolar macrophages that present mycobacterial antigens to antigen-specific $\mathrm{CD} 4^{+}$ cells (18). This is via several cytokines, which are inflammatory mediators produced by macrophages, monocytes, and lymphocytes. When these cells are sensitized by prior exposure to MTB, and then reexposed to the same antigens, they produce several cytokines such as interferon-gamma (IFN- $\gamma$ ), interleukin 6 (IL-6), IL-12, and IL-18 $(28,29)$. This is a Thlcell-mediated immune response; it is typical for TB and other intracellular pathogens. This is in contrast to asthma and other atopic diseases whose response is Th2 cell-mediated with different cytokines, like IL-4 and IL-5 (30). Mycobacteria! infected macrophage releases IL-12 and 18 , these cytolines stimliate $\mathrm{CD}^{+}$ 
lymphocytes to release IFN- $\gamma(31 \& 32)$, which in turn activate more macrophages to enhance their ability to contain mycobacterial infection. The activated macrophages also release tumor necrosis factor (TNF- $\alpha$ ), IL-1 and IL-6, it is these set of cytokines that enhance viral replication (26,33-36). Tubercle bacilli and their products also enhance viral replication by inducing nuclear factor kappa-B (NF-kB), this cellular factor binds to promoter regions of HIV (37\&38) and TNF- $\alpha$-induced-HIV replication is mediated predominantly through the increased activation of this factor (39\&40). The long terminal repeat (LTR) of HIV contains 2 NF${ }_{\mathrm{K}} \mathrm{B}$ sites, and $\mathrm{NF}_{-\mathrm{k}} \mathrm{B}$, either alone (41) or in concert with other transcription factors (42), is critical to the transcriptional activation of HIV. Activation of mitogen-activated protein (MAP) kinase pathway has also been implicated in the increased HIV replication (43). In particular, the p38 MAP kinase pathway has been found to be critical in HIV replication in both CD4+ cells (43) and macrophages (44). IL-1 $\beta$ and TNF- $\alpha$ activate $p 38$ MAP kinase and the HIV-1 LTR (45), and these cytokines are up-regulated by the MTB infection of mononuclear phagocytes (46\&47). $\beta$-chemokine, monocyte chemotactic protein (MCP-1) are also known to play active roles in enhancing HIV replication (48). The recovered broncho-alveolar fluid from TB affected lung has demonstrated local increase in HIV replication by containing higher level of viral load compared to the unaffected segment of the lung and this correlated with TNF- $\alpha$ suggesting local production of the virus (49). The local immune activation against TB also favours the development of latent HIV infection in the mactophages and dendritic cells, thereby potentially enhancing dissemination of HTV (50\&51) Thus in HIV-infected persons with active TB, the active sites of TB infection act as epifoci of increased HIV replication and evolution independent of systemic HIV disease activity (50). The resulting HIV viraemia will deplete immune cells that play a central role in anti-mycobacterial defenses (52); such $\mathrm{CD}^{+}$lymphocytes, macrophages and monocytes. MTB is characterized by delayed-type hypersensitivity reaction and granuloma formation in the infected tissues. Resolution of this granuloma is controlled by both cell-mediated immunity and delayed-type hypersensitivity reaction, both of which are often accompanied by some level of tissue destruction (24). Cell-mediated immunity controls TB by activating macrophages to kill ingested bacilli while delayed-type hypersensitivity causes caseous necrosis that result in killing of bacilli-laden macrophages (53). Some of the granulomas may undergo necrosis and sloughs. off forming cavities others may heal with fibrosis and some may calcify (54). The extent of necrosis and cavitation in HIV/TB patients is dependent on the relative efficacy of each of these two immunologic processes in inhibiting multiplication of MTB. However, both processes are reduced in this circumstance.

\section{PATTERN OF TB IN HIV INFECTION: The} location and pattern of distribution of TB in HIV/TB patients is a measure of their level, of immunity (18). In the earlier stages of HIV disease the clinical features is typical and similar to that seen in HIV negative patients. The manifestation is often pulmonary with infiltrates and cavitations in the apical posterior segments of the upper lobe and the superior segment of the lower lobe of the lungs. As the level of immunosuppression increases the presentation becomes atypical resembling primary TB with interstitial non-cavitary lesions because of poor granuloma formation and these involve more of the lower lung fields (55). At the terminal stage of HIV/AIDS extra pulmonary presentation 
involving single or multiple sites are commoner along with miliary and disseminated disease i.e., involvement of two or more non-contagious sites

\section{DIAGNOSIS}

Definitive diagnosis of TB in HIV infected patients requires the isolation and identification of MTB from the culture of the infected tissue or fluid; a presumptive diagnosis is often made from microscopic observation of acid-fast bacilli (AFB) in the stained smear of sputum (56). AFB are rod shaped organisms with large amount of lipid in their cell walls making them difficult to stain but once stained resist decolourization even when washed with $95 \%$ alcohol containing $3 \%$ hydrochloric acid, thus the characteristic acid-fast property (57\&58). Laboratories diagnosis is by. Ziehl-Neelson (ZN) or Kinyoun or Tan Thiam Hok staining procedures all of which utilize carbolfuschin (57). The former is heat fixed while the latter two are cold staining methods that require increased concentration of phenol in the staining solution. $\mathrm{ZN}$ staining with light microscope is the most commonly used methods of the three, it is however, time consuming and have low sensitivity requiring at least $10(5)$ of tubercle bacilli per $\mathrm{ml}$ of specimen for reliable routine diagnosis (58). However, auramine-rhodamine staining technique with fluorescence microscope is a much faster and sensitive alternative. Properly collected sputum smears that fail to demonstrate AFB do not exclude the diagnosis of TB; because post-primary TB, the main source of infection, or re-infection in a given population is smear positive in about $50 \%$ of cases (3\&59) while primary and miliary TB are smear positive in less than $25 \%$ of the cases (60\&61). These percentages decrease further in the HIVsetopositive population because of their lower propensity to develop cavitary disease. Invasive procedures such as bronchoscopy with transbronchial biopsy may be necessary to establish the diagnosis of TB in them because of this high rate of smear negative PTB and increasing cases of extra pulmonary TB (EPTB) as well as other opportunistic diseases that may resemble TB in presentation (62-64). MTB can be differentiated from other mycobacterials that could equally infect HIV/AIDS patients by culture (65), but the commonly used Lowenstein-Jensen culture agar requires 4-8 weeks for adequate growth to allow identification (66). Recent improvement in methods of mycobacterial specification is with the use of radiometric technique (BACTEC method). The technique uses radio labeled palmitic acid, a substrate that is metabolized to released (14) $\mathrm{CO}_{2}$, which is quantified to identify presence and growth of the mycobacteria (66\&67); The BACTEC system allows detection of $M T B$ growth with a mean detection time of 7-13 days for smearpositive and 14-22 days for smear-negative sputum specimens (65). Rapid diagnosis of TB is also possible with molecular amplification and identification of $M T B$ specific DNA or ribosomal RNA sequences by polymerase chain reaction (68). For epidemiologic purposes, patterns of infection within a population. could be studied, with identification of the points of transmission by restriction fragment length polymorphism also referred to as "DNA fingerprinting," this is a molecular biology technique that allows differentiation of unrelated strains of $M T B$ by demonstration of nucleotide sequence differences at selected sites in their DNA genome (69).

WHO recently advocated the screening of all TB patients for HIV infection, but this has not been universally accepted by the clinicians especially in the developing countries for reasons that include; increase in the cost of patients care (70), regional variation in the prevalence of the TB/HIV coinfection (7) and the fact that DOTS if properly 
implemented is effective in curing TB in most patients regardless of their HIV status (17). However, offering voluntary counseling and HIV testing (VCT) to TB patients is beneficial because early diagnosis of HIV infection in TB patients has been associated with a good prognosis in terms of TB cure and it minimizes the negative effect of TB on the course of HIV (71). Patients could as well plan for the future. HIV co-infection should therefore be suspected in TB patients with history of risky life style, or in a TB patient that does not show prompt sputum conversion while on standard anti-TB regimen. It should also be considered in TB patients with chronic diarrhea or mucocutaneous lesions such as or oral thrush. multidermatomal herpes zoster, non specific generalized dermatitis or co-existing sexually transmitted disease. Patients with extra pulmonary or disseminated TB should also be evaluated for dual infection. These categories of TB patients should be offered VCT.

\section{TREATMENT}

Short course of anti-TB chemotherapy is as effective in HIV positive TB patients as it is in the HIV negative ones, sputum conversion is rapid and cure rate is good (72). However, drug compliance is often very poor (73) and this could encourage emergence of potentially incurable multidrugresistant TB (MDR-TB). This is however, common in poorly managed TB control programmes, especially those that lack the basic elements of good control (74), (prevalence of MDR-TB in Vigeria is $1.7 \%(7)$ ). Successful treamemt of TB in $\because \vee$ patients therefore, depends on eary diagnosis ex e:Tective application of DOTS where ant-TB wr! be free and patients observed to shallow each pill. In order to increase patients' easy access to free ARV drugs the existing local DOTS infrastructure could be utilized to deliver both medications in a DOT-HAART programme (75).
However, where DOTS is not fully feasible, selfsupervised patient-centered care should be encouraged to forestall non-compliance. Current guidelines (74\&76) recommend that HIV infected patients with drug susceptible TB be started on the standard six-month regimen of four drugs and that treatment should be initiated with isoniazid $(\mathrm{INH})$, rifampicin/ rifabutin, pyrazinamide and cthambutol, all in $\mathrm{mg} / \mathrm{kg}$ body weight for the first 2 months followed by rifampicin and $\mathrm{INH}$ for the subsequent 4 months. Intermittent anti-TB drug administration is not advisable in the management of HIV/TB and if it is to be adopted at all, the thrice weekly regimen should only be tried during the continuation phase of therapy (77). However, daily drug intake is preferred to the intermittent regimen so as to prevent development of MDR-TB (74\&76). Response of HIV/TB patients to this 6month therapy has been found to be good with similar recurrent rate to that of HIV-negative patients (78\&79) A higher recurrence rate was however. found in one report (80), but this was ascribed to re-infection rather than treatment failure. A multi-centered sudy may be needed to compare the outcome of short course anti-TB management in HIV patients with early and well advanced disease (81). At the interim, prolongation of the continuation phase to 7 months to make a total of 9 months of treatment has been suggested if there is evidence of a delayed clinical or bacteriological response to therapy (74\&76). The practice of extended post-treatment INH therapy to prevent recurrence of TB in HIV patients has not been widely accepted though some have found it effective (82). The same principles of treatment for PTB in HIV infected adults also apply to EPTB. The drug regimens and treatment durations are the same (76\&83). However, for certain forms of EPTB, such as TB meningitis, bone, or joint, using rifamycin-based regimens for at least 9 months is 
generally recommended (76\&83). A nonrifampicin based anti-TB regimen comprising $\mathrm{INH}$, pyrazinamide and ethambutol is generally not recommended for treatment of HIV-related TB, but in cases of rifampicin intolerance, severe allergy or toxicity, this regimen should be administered daily for 18 months (83).

In order to limit mortality from HIV/TB coinfection anti-TB drugs may have to be coadministered with antiretroviral (ARV) drugs in those with advanced disease (84). However, treatment of TB should be given priority if possible to avoid drug induced hepatic reactions from the dual potential hepatotoxic combinations. Initiation of ARV should be based on CD4 ${ }^{+}$count and risk of disease progression (74\&76). There is yet to be a consensus on the time to introduce ARV. Tables 1 and 2, show that commencement of ARV in HIV/TB should be individualized and balanced between potential overlapping drug toxicities, drug-drug interactions and increasing TB morbidity from immune reconstitution reactions, against the reciprocal beneficial effect each therapy have on each other, which is to the benefit of the patients (74\&76). HAART improve immune responses to TB and reduces the risk of relapse and re-infection, while anti-TB drugs results in quick lowering of the viral load thereby reducing the rate of $\mathrm{CD4}^{+}$ cells loss (85\&86). Good as this combination therapy may sound, it is associated with bidirectional pharmacokinetic interactions between the rifamycin components of anti-TB regimen and the protease inhibitors (PIs) and non-nucleoside reverse transcriptase inhibitors (NNRTIs) components of antiretroviral therapy (87). Therefore diligent consideration of choice of drugs becomes imperative to prevent or minimize these drug-drug interactions. PIs and NNRTIs may inhibit or induce hepatic cytochrome (CYP-450) isoenzymes and thus alter the serum concentration of rifamycins (87). Rifamycins in turn can induce CYP-450 and therefore substantially decrease blood levels of the ARV drugs too Rifampicin is the most potent CYP-450 inducer of all the rifamycins (88), followed by rifabutin, rifapentine has an intermediate activity (89\&90). Only rifampicin is currently available in Nigeria. All the PIs inhibit CYP-450 (91\&92) with ritonavir as the most potent and saquinavir as the least potent while indinavir, nelfinavir have intermediate inhibitory properties. The available NNRTIs have diverse effects on CYP-450: nevirapine is an inducer, delavirdine is an inhibitor, and efavirenz is both an inducer and an inhibitor (92\&93). In contrast to the PIs and the NNRTIs, the other class of ARV drugs, NRTIs; zidovudine, didanosine, zalcitabine, stavudine, and lamivudine are not metabolized by CYP-450, therefore, concurrent use of NRTIs and rifamycins is not contraindicated. Also, no contraindication exists for the use of NRTIs, NNRTIs, and PIs with INH, pyrazinamide, ethambutol, or streptomycin. These first-line antiTB medications, in contrast to the rifamycins, are not CYP-450 inducers or inhibitors. Commonly prescribed ARV for co-infected patients in Nigeria includes zidovudine or stavudine with lamivudine and efavirenz, other approved combinations are also possible as most of the HAART drugs are now available in the country. Efavirenz is contraindicated in pregnant women becalse of it teratogenicity. Squanvir / ritonovir or abacavir with stavudine or zidovudine and lamivudine are the alternative to it.

Adjunct therapy with cytokine inhibitors may have a rule in the management of HIV/TB coinfection (94) to limit HIV replication before initiation of ARV. Thalidomide, a specific TNF- $\alpha$ inhibitor and pentoxifylline a nonspecific inhibitor have been tried (95). However, inhibition of TNF$\alpha$ was associated with profound immune defects 
akin to that of advanced AIDS and these predisposed patients to reactivation of old TB, which progressed to, disseminated form (95). Full understanding of the role of cytokines inhibition in the pathogenesis of reactivation of TB in HIV/TB is therefore required. Good nutrition, including food supplements will serve as essential adjuncts to ant:-TB chemotherapy.

\section{PATIENTS MONITORING. All HIV/PTB} patients should be monitored by sputum smear microscopy during treatment and if available, sputum culture and susceptibility testing. HIVEPTB should also be monitored, but the frequency and types of evaluations will depend on the involved sites and the ease with which specimens can be obtained from these sites ( 81 ). In resource limited countries, a monthly clinical assessment has been recommended for three months followed by 3-6 monthly clinical evaluation (96) to monitor improvement, ARV adherence and to identify possible drug reaction (96). Clinical and laboratory assessment should be more frequent for patients with underline liver disease. In "most developing countries viral load measurement is unavailable and monitoring of therapy is by regular clinical assessment for signs "of $f_{s,}$ disease regression, increasing body weight and rising $\mathrm{CD} 4^{+}$count (97). Laboratory monitoring is prioritized by observing the trimmed down WHO guidelines for HIV treatment in poor countries (98). These are inexpensive tests that have been divided into basic and desirable tests and include haemoglobin, white cells and total lymphocyte court. live enzymes and $\mathrm{CD4}^{+}$cells. These should be done every 3roths. Serum amylase, bilirubin and lipids are ziso desirable but optional (98). Some HN TB perients could experience temporary exacertation of symptoms and signs of TB, and some may stom worsening of the radiographic features of TB at the beginning of anti-TB treatment. This phenomenor is termed a paradoxical (or immune reconstitution) reaction (96). It could also occur among HIV negative TB patients, but it is commoner amongst HIV/TB co-infected while on HAART (99). Features of a paradoxical reaction include high fevers, increase in size and inflammation of involved lymph nodes, new lymphadenopathy, expanding central nervous system lesions, worsening of pulmonary parenchymal infiltrations, and increasing pleural effusions (99). A reaction that is not severe should be treated symptomatically with non-steroidal anti-inflammatory

agents without a change in anti-TB or ARV therapy (100\&101). Those with severe reactions (e.g. airway compromise from enlarging lymph nodes, enlarging serosal fluid collections, and sepsis syndrome) may benefit from the prednisone or methylprednisolone $1 \mathrm{mg} / \mathrm{kg}$ body weight and gradually reduced after $1--2$ weeks (100\&101).

\section{CHEMOPROPHYLAXIS.}

Chemoprophylaxis against TB in HIV positive patients may not be strongly advocated in a developing country like Nigeria whete TB is an endemic problem. The value of a positive tuberculin test may also be difficult to determine because BCG is routinely administered at birth. In addition INH prophylaxis may be abuse and this could encourage INH-resistance when decision is finally made to treat active TB. 
Table 1. WHO. Suggested timing of HAART in HIV/TB co-infection (WHO- Dec 2003)

\begin{tabular}{|c|c|c|}
\hline Cd4+ count & Recommended regimen & Comment \\
\hline $\mathrm{CD} 4+<200 / \mathrm{mm}^{3}$ & $\begin{array}{l}\text { Start TB treatment as soon as } \\
\text { possible }\end{array}$ & $\begin{array}{l}\text { Start ARV as soon as anti-TB is } \\
\text { tolerated. EFV is contraindicated } \\
\text { in pregnant women. }\end{array}$ \\
\hline $\mathrm{CD} 4+200-350 / \mathrm{mm}^{3}$ & Start TB treatment. & $\begin{array}{l}\text { Start ARV after intensive phase } \\
\text { of anti-TB. }\end{array}$ \\
\hline $\mathrm{CD} 4+>350 / \mathrm{mm}^{3}$ & Start TB treatment & Defer ARV* \\
\hline CD4+ not available & Start TB treatment & Consider ARV** \\
\hline *Unless non-TB stage & are present. Otherwise start ART & pon completion of $T B$ treatment. \\
\hline
\end{tabular}

Table 2. BHIVA. Suggested tinigng of HAART in HIV/TB co-bection

CD4+ count cells/uL When to treat with HAART

$<100$

As soon as possible-dependent on physician assessment,

[Some physicians delay up to 2 months]

$100-200$

After 2 months of TB treatment

$>200$

After completing 6 months TB treatment*

http://www.bhiva.org * BHIVA treatment guidelines for TB/HIV infection - February 2005 


\section{REFERENCES}

1. Yoga TA. TB and HIV infection available at:

http://www.medicalprogress.com/dispdf.cfm?f name $=M P o c t 2005 T B$ And Human Immunod eficiency.pdf.

2. Joint United Nations Programme on HIV/AIDS (UNAIDS) and World Health

Organization (WHO) 2002. AIDS Epidemic Update December 2004. UNAIDS/

04.45E.Geneva: UNAIDS; 2004.

3. Sharma SK, Mohan A, Kadhiravan T. HIV/TB co-infection: Epidemiology, diagnosis and management. Indian J Med Res. 2005; 121 : 550-567

4. WHO. TB/HIV. Available at: http://www. who.int/tb/hivien!

5. WHO. TB/HIV co-infection. Available at: http://www.cde.gov/nchstp/tb/pubs/TB_HIVco infection/default.htm

6 Cantwell MF, Binkin NJ. TB in sub-Saharan Africa: a regional assessment of the impact of the human immunodeficiency virus and National TB Control Program quality. Tuber Lung Dis 1996 Jun;77:220-225.

7. Global

TB

control -

surveillance, planning,

financing. WHO. 2005

http://www, who.int/entity/tb/publication/globa 1 reporten/

8. Report on the Integration of TB and HIV services in Site B Khayelitsha, South Africa. Available

http://www.msf.org.auidocs'reportsitb integrat an report 022005.pdf

- Coriet EL, Watt CJ,"Walket N, a al. The enwing burden of TB: global trends and meractions with the HIV epidemic. Arch Intern Med 2003;163:1009-1021.
10. Centers for Disease Control and Prevention. Guidelines for preventing the transmission of $M T B$ in health-care facilities. MMWR

Morbity Mortality Wkly Rep 1994; 43(RR13):1-132.

11. Cantanzaro A. Nosocomial TB. Am Rev Resp Dis.1982;125: 559-562.

12. Malasky C, Jordan $\mathrm{T}$, Potulski $\mathrm{C}$ et al. Occupational tuberculous infections among pulmonary physician in training. Am Rev Resp Dis. 1990; 142:505-507

13. Calder RA, Duclos P, Wilder MH et al. MTB transmission in a health clinic. Bull Int Union Tuber Lung Dis. 1991;66:103-106.

14. Hutton MD, Stead WW, Cauthen GM et al. Nosocomial transmission of

TB associated with a draining abscess. $J$ infect Dis. 1990;161: 286-295.

15. Frampton MW. An outbreak of TB among hospital personnel caring for a patient with a skin ulcer. Ann Intern Med. 1992;117:312313.

16. Lillebaek T, Dirksen A, Baess I et al. Molecular evidence of endogenous reactivation of MTB after 33 years of latent infection. J Infect Dis 2002; 185:401-404.

17. Quraishi SY. The HIV/TB co-infection, available at: http://www.nacoonline.org/guidelines/HIV/TB guidelines.pdf

18. Schluger NW, Rom WN. The host immune response to TB. Am J Respir Crit Care Med 1998; $157: 679-691$

19. Lucas S, Nelson AM. Pathogenesis of TB in human immunodeficiency virus-infected people. In: Bloom BR, ed. TB: pathogenesis, protection, and control. Washington, DC: 
American Society for Microbiology Press, 1994:503-513

20 Havlir DV, Barnes PF. TB in patients with human immunodeficiency virus infection. $N$ Engl J Med 1999;340 : 367-373.

21. Daley CL, Small PM, Schecter GF et al. An outbreak of TB with accelerated progression among persons infected with the human immunodeficiency virus: an analysis using restriction fragment length polymorphisms. $N$ Engl J Med 1992; 326 : 231-235.

22. Sonnenberg P, Murray J, Glynn JR et al. HIV-1 and recurrence, relapse, and reinfection of TB after cure: a cohort study in South African mineworkers. Lancet2001;358 : 1687-1693.

23. Cotran RS, Kumar V, Robin SL. Robin pathologic basis of diseases, $4^{\text {th }}$ edition, WD Saunders, Philadelphia. 2000:780-832.

24. Allen EA. TB and other mycobacterial infections of the lung. In: Thurlbeck WM. Churlbeck AM, eds. Pathology of the lung 2nd ed. New York, NY: Thieme Medical, 1995; 229-265.

25. Goodwin RA, DesPrez RM. Apical localization of pulmonary TB, chronic pulmonary histoplasmosis, and progressive massive fibrosis of the lung. Chest 1983; 83:801-805.

26. Toossi Z. Cytokine circuits in TB. Infectious Agents and Disease 1996;5:98-107.

27. Goletti D. Effect of MTB on HIV replication: role of immune activation. $\mathrm{J}$

Immunol. 1996;157: 1271-1285.

28. Anderson P, Munk ME, Pollock S, Doherty TM. Specific immune-based diagnosis of TB. Lancet.2000;356:1099-1104.

29. Taha RA, Minshall EM, Olivenstein R, Ihaku D, Wallaert B, Tsicopoulos A et al. Increased Expression of IL-12 Receptor mRNA in Active Pulmonary TB and Sarcoidosis. Am J Resp
Crit Care Medicine 1999; 160:1119-1123.

30. Surcel HM, Troye-Blomberg M, Paulie.S, Anderson G, Moreno $C$, Passvol $G$ et al. TD1/TD2 profiles in TB, based on the proliferation and cytokine response of blood lymphocytes to mycobacterial antigens. Immunology 1994; 81:171-176.

31. Sodhi A, Gong J, Silva C et al. Clinical correlates of interferon-gamma production in

patients with TB. Clin Infect Dis 1997; 25: 617-620.

32. Ellner JJ. Review: The immune response in human TB: implications for

TB control. J Infect Dis 1997; 176: 1351-1359.

33. Duh EJ, Maury WJ, Folks TM et al. Tumor necrosis factor alpha activates human immunodeficiency virus type 1 through induction of nuclear factor binding to the NFkappaB sites in the long terminal repeat. Proc Viatl Acad Sci USA 1989;86:5974-5978.

34. Yoli G Bressler $P$, Kinter A, et al. Interleukin 6 induces human immunodeficiency virus expression in infected monocytic cells alone and in synergy with tumor necrosis factor alpha by transcriptional and posttranscriptional mechanisms. \& Exp Med 1990;172:151-158.

35. Folks TM, Justement $J$, Kinter $A$ et al. Cytokine-induced expression of HIV-1 in a chronically infected promonocyte cell line. Science 1987;238:800-802.

36. Osborn L, Kunkel S, Nabel GJ. Tumor necrosis factor alpha and interleukin 1 stimulate the human immunodeficiency virus enhancer by activation of the nuclear factor $\mathrm{kB}$. Proc Natl Acad Sci USA 1989;86:2336-2340.

37. Lederman MM, Georges DL, Kusner DJ et al. MTB and its purified protein derivative activate expression of the human 
immunodeficiency virus. J Acquir Immune Defic Syndr 1994;7:727-733.

38. Zhang $Y$, Nakata $K$, Weiden $M$ et al. MTB enhances human immunodeficiency virus1 replication by transcriptional activation at the long terminal repeat. J Clin Invest 1995;95:2324-2331.

39. Schutze $\mathrm{S}$, Machleidt $\mathrm{T}$, Kronke $\mathrm{M}$. Mechanisms of tumor necrosis factor action. Semin Oncol 1992; 19:16 24 .

40. Toossi $Z$, Hamilton BD, Phillips $M H$ et al. Regulation of nuclear factor-kappa $B$ and its inhibitor I kappa B-alpha/MAD-3 in monocytes by $M T B$ and during human TB. J Immunol 1997; 159:4109-4116.

41. Jeang KT, Xiao H, Rich EA. Multifaceted activities of the HIV-1 transactivator of transcription, Tat. J Biol Chem 1999, 274:28837-28840.

42. Pereira LA, Bentley K, Peeters A et al. A compilation of cellular transcription factor interactions with the HIV-1 LTR promoter. Nucleic Acids Res 2000; 28:663 - 668.

43. Cohen PS, Schmidtmayerova H, Dennis J, et al. The critical role of $\mathrm{p} 38$ MAP kinase in $\mathrm{T}$ cell HIV-1 replication. Mol Med 1997; 3:339-346.

44. Shapiro L, Heidenreich KA, Meintzer MK et al. Roke of p38 mitogen-activated protein kinase in HIV type 1 production in vitro. Proc Natl Acad Sci USA 1998: 95:7422 7426.

45.. Kumar S, Orsini MJ. Lee JC et al. Activation of the HIV-1 long terminal repeat by cytokines and environmental stress requires an active CSBP/p38 MAP kinase. J Biol Chem 1996; 2-1:30864-30869.

46. 49Valone SE, Rich EA, Wallis RS et al. Expression of tumor necrosis factor in vitro by human mononuclear phagocytes stimulated with whole Mycobacterium bovis BCG and mycobacterial antigens. Infect Immun 1988; 56:3313-3315.

47. SoWallis RS, Fujiwara H, Ellner JJ. Direct stimulation of monocyte release of interleukin 1 by mycobacterial protein antigens. $J$ Immunol 1986; 136:193-196

48. Sadek MI, Sada E, Toossi $Z$ et al. Chemokines induced by infection of mononuclear phagocytes with mycobacteria and present in lung alveoli during active pulmonary TB. Am J Respir Cell Mol Biol 1998; 19:513-521.

49. Toossi Z, Johnson JL, Kanost RA et al. Increased replication of HIV-1 at sites of MTB infection: potential mechanisms of viral activation. J Acquir Immune Defic Syndr $2001 ; 28: 1-8$.

50. Toossi Z. Virological and immunological impact of TB on human

immunodeficiency virus type 1 disease. $J$ Infect Dis 2003; 188 : 1146-1155.

51. Nakata $\mathrm{K}$, Rom WN, Honda $\mathrm{Y}$ et al. MTB enhances human immunodeficiency virus-1 replication in the lung. Am $J$ Respir Crit Care Med 1997; 155 : 996-1003

52. Chakraborty MS, Chakraborty A. TB and HIV illness. J Indian Med Assoc. 2000;98: 103-106.

53. Dannenberg AM, Jr. Delayed-type hypersensitivity and cell-mediated immunity in the pathogenesis of TB. Immunol Today 1991; 12:228-333.

54. Madebo T. Clinical and operational challenges in the control of TB in south Ethiopia available at http://www.lunge.no/files/lungehel/tesfayeavhandligen.pdf.

55. Perlman DC, el-Sadr WM, Nelson ET et al. Variation of chest radiographie patterns in pulmonary TB by degree of human immunodeficiency virus- related 
immunosuppression. The Terry Beim Community Programs for Clinical Research on AIDS (CPCRA). The AIDS Clinical Trials Group (ACTG). Clin Infect Dis 1997; 25 : $24 \hat{\imath}-24 \hat{C}$

56. Onile BA, Nwofor AC, Oluboyo PO et al. Comparison of microscopy and cultural methods for the diagnosis of pulmonary TB in llorin. Nig Qt J Hosp Med.1997; 7:227-229

57. Westley AV. Essential of medical microbiology. $1^{\text {st }}$ edition, Lippincort company. New York. 1978: pages 344-345.

58. Mcnerney R. TB Diagnosis: present difficulties and prospects for the future. Afr Hlth.1996; 19:22-23.

59. Shaw JB, Wynn-William N. Infectivity of patients with pulmonary $\mathrm{TB}$ in relation to sputum status. Am Rev Respir Dis 1954;69:724-732.

60. Hudson CP, Wood R, Maartens G. Diagnosing HIV-associated TB: reducing costs and diagnostic delay. Int I Tuberc Lung Dis 2000; 4:240-245.

61. Hudson CP. Wood R. Ultrasound for the diagnosis of HIV-associated TB. S Afr Med J 2003: 93:440-441.

62. Hopewell PC. A clinical view of TB. Radiol Clin North Am 1995; 33:641-653.

63. Orlovic D, Kularatne R, Ferraz $V$ et al. Dual pulmonary infection with MTB and Pneumocystis carinii in patients infected with human immunodeficiency virus. Clin Infect Dis 2001; 32 : 289-294.

64. Burk JR, Viroslav J, Bynum LJ. Miliary TB diagnosed by fiberoptic bronchoscopy and transbronchial biopsy. Tubercle 1978; 59:107109.
65. Herold CD, Fitzgerald RL, Herold DA. Current techniques in mycobacterial detection and speciation. Crit Rev Clin Lab Sci 1996; 33:83138.

66. Bass JR, Jr, Farer LS, Hopewel! PC et al. Diagnostic standards and classification of TB. Am Rev Respir Dis 1990; 142:725-735.

67. Watterson SA, Drobniewski FA. Modern laboratory diagnosis of mycobacterial infections. J Clin Pathol 2000; 53 : 727-732

68. Marshall BG, Shaw RJ. New technology in the diagnosis of TB. Br J Hosp Med 1996; $55: 491-494$.

69. van Soolingen $D$, Hermans PWM. Epidemiology of TB by DNA fingerprinting. Eur Respir J 1995; 20:649S-656S.

70. Okoro EO. Mandatory HIV testing in pulmonary TB. Nig J Genito-urinary Med. 2004:3\&4:66-67.

76. CDC. Prevention and treatment of TB among patients infected with human immunodeficiency virus: principles of therapy and revised recommendations. MMWR 1998;47(no. RR-20).

72. Brindle RJ, Nunn PP, Githui $W$ et al. Quantitative bacillary response to treatment in HIV-associated pulmonary TB. Am Rev Respir Dis 1993;147:958-961.

73. Salami AK, Oluboyo PO: Management outcome of pulmonary TB. West Afr J Med. 2003;22: 114-119.

74. Blumberg HM, Burman WJ, Chaisson RE et al. American Thoracic Society, Centers for Disease Control and Prevention and the Infectious Diseases Society of America: treatment of TB. Am J Respir Crit Care Med 2003; 167: 603-662. 
75. Farmer $P$, Leandre $F$, Mukherjee $J$ et al. Community-based treatment of advanced HIV disease: introducing DOT-HAART (directly observed therapy with highly active antiretroviral therapy). Bull World Health Organ 2001:79:1145-1151.

76. British HIV Association. BHIVA treatment guidelines for TB/ HIV infection September 2004; p. 1-32. Available at http:// www.bhiva.org.

77. CDC. Acquired rifamycin resistance in persons with advanced HIV disease being treated for active $T B$ with intermittent rifamycin-based regimens. MMWR 2002;51:214-215.

78. Korenromp EL, Scano F, Williams BG et al. Effects of human immunodeficiency sirus infection on recurrence of TB after rifampicinbased treatment: an analytical review. Clin Infect Dis 2003; $37: 101-12$.

79. Perriens JH, St Louis ME, Mukadi YB et al. Pulmonary TB in HIV-infected patients in Zaire. A controlled trial of treatment for either 6 or 12 months. N Engl J Med 1995; 332 : 779-784.

80. El-Sadr WM, Perlman DC, Denning E et al. A review of efficacy studies of 6-month short course therapy for TB among patients infected with human immunodeficiency virus: differences in study outcomes. Clin Infect Dis 2001;32: 623-632.

81.CDC. 2004: Treating Opporiunistic Infections Among HIV-Infected Adults and Adolescents; available at: htp: $/ /$ www.cdc.gov/mmwr/preview/mmwhtm li mm5315al.htm

82. Fitzgerald DW, Desvarieux $M$, Severe $P$ et al. Effect of post-treatment isoniazid on prevention of recurrent TB in HIV-1-infected individuals: a randomised trial. Lancet 2000;356: 1470-1474.

83. Htay Z. Management of TB in HIV infected patients.

Available at:

http://www.demsonlinc.org/jaxmedicine/1999joumal siaugust99/tb.htm

84. World Health Organization. Scaling up antiretroviral therapy in resource-limited settings: treatment guidelines for a public health approach. 2003 revision. Geneva: World Health Organization; 2004 p. 40-42.

85.Centers for Disease Control and Prevention. Prevention and treatment of TB among patients infected with human immunodeficiency virus: principles of therapy and revised recommendations. MMWR Morb Mortal Wkly Rep 1998; $47: 1-25$.

86. Dean GL, Edwards SG, Ives NJ et al. Treatment of TB in HIVinfected persons in the era of highly active antiretroviral therapy. AIDS 2002: $16: 75-83$.

87.Piscitelli SC. Gallicane KD. Interactions among drugs for HIV and opportunistic infections. $\mathrm{N}$ Engl J Med 2001; 344 : 984-996.

88. Heylen R, Miller R. Adverse effects and drug interactions of medications commonly used in the treatment of adult HIV positive patients \{Review\}. Genitourinary Medicine 1996;72:237-246.

89. Perucca E, Grimaldi R, Frigo $G M$ et al. Comparative effects of rifabutin and rifampicin on hepatic microsomal enzyme activity in normal subjects. Eur $\mathbf{J}$ Clin Pharmacol 1988;34:595-599.

90. Durand DV, Hampden C, Boobis AR et al. Induction of mixed function oxidase activity in man by rifapentine (MDL 473), a long-acting 
rifamycin derivative. $\mathrm{Br} \mathrm{J}$ Clin Pharmacol 1986:21:1-7.

91. Fagling VA, Back DJ, Barry MG. Differential inhibition of cytochrome P450 isoforms by the protcase inhibitors, ritonavir, saquinavir and indinavir. Br J Clin Pharmacol 1997:44:190194.

92. Woolley J, Studenberg S, Boehlert $C$ et al Cytochrome P-450 isozyme induction. inhibition, and metabolism studies with the HIV protease inhibitor, 141W94 \{Abstract\}. In Program and abstracts of the 37 th Interscience Conference on Antimicrobial Agents and Chemotherapy. Toronto, Ontario; 1997:A-60.

93. Benedek IH, Joshi A, Fiske WD, et al. Pharmacokinetic interaction between efavirenz and rifampin in healthy volunteers \{Abstract\}. In Program and abstracts of the 12th World AIDS Conference. Geneva, Switzerland, 1998:829.

94. Ellner JJ. The interaction between HIV and Mycobacterium tuberculosis. Conf Retroviruses Opportunistic Infect 1997 Jan 2226; 4th:216 (abstract no. S21)

95. Keane J, Gershon S, Wise RP, Mirabile-Levens E, Kasznica J, Schwieterman WD et al. Tuberculosis associated with infliximab, a tumor necrosis factor a - neutralizing agent. The New England Journal of Medicine 2001; 34515:1098-1104

96. Anne-christine d'adesky. WHO pares down HIV treatment guidelines for poor countries. Available at: http://www.acgis.com/pubs/amfar/2002/AM02 0701.htnl
97. Salami AK, Olatunji PO, Fawibe EA. Influence of Highly Active Antiretroviral Therapy (HAART) on the Survival of HIV-Infected Patients: Part Report of the Ilorin Trial Center. Afr J Clin Exptal Microbiol.2004;6:34-39

98. WHO. Antiretroviral newsletter Issue no.4. Clinical and laboratory monitoring of antiretroviral therapy in resource-limited and unlimited settings. Available at: http:/www.wpro.who.int/NR/rdonlyres/DFC8 8S4E-1EA8-4B06-B04A4E05797FI7EE 0 ART. Newsictter Issuc 4.p df

99. Narita M, Ashkin D, Hollender ES, Pitchenik AE. Paradoxical worsening of TB following antiretroviral therapy in patients with AIDS. Am J Respir Crit Care Med 1998;158:157-161.

100. DeSimone JA, Pomerantz RJ, Babinchak TJ. Inflammatory reactions in HIV-1--infected persons after initiation of highly active antiretroviral therapy. Ann Intern Med $2000 ; 133: 447-454$.

101. Navas E, Martín-Dávila P, Moreno L, et al. Paradoxical reactions of TB in patients with the acquired immunodeficiency syndrome who are treated with highly active antiretroviral therapy. Arch Intern Med 2002;162:97-99. 